\title{
PENGAPLIKASIAN WARNA FOUNDATION TERHADAPKULIT WAJAH GELAP PADA RIAS PESTA
}

\author{
Muzakiyah Qurrata A'yuni1 ${ }^{1}$, Hayatunnufus ${ }^{2}$ \\ 1,2 Program Studi Pendidikan Tata Rias Dan Kecantikan \\ Jurusan Tata Rias dan Kecantikan \\ Fakultas Pariwisata Dan Perhotelan \\ Universitas Negeri Padang \\ e-mail : mozakiyah@gmail.com
}

Abstract

The difficulty in choosing Foundation colors is very influential for the makeup of one of them is makeup party. Because the wrong in choosing foundation colors make a striped face does not correspond to the skin color. The purpose of this study is to determine the difference in the foundation color application against the skin of dark face on party makeup.This type of research is a pseudo experiment (quasi experiment) with the research design of Non-Equivalent Control Group design. The inside object of the study is a woman who has a dark skin 18-25 years old with a sample number of 3 people. The data analysis techniques used are test normality, homogeneity test and Anava test.Based on the research result of foundation color application against the skin of dark face on party makeup seen from the foundation level grading indicators and the foundation color conformance level. Foundation color application Results One level brighter has an average level of smoothness 2.28 level of foundation color conformity has an average of 2.14. Foundation Color application Result one-level darker level of smoothness has an average of 2.14 foundation color conformity 2.28. The results of the application of two colors foundation one level lighter mixing with one level darker the level of smoothness has an average of 3.28 the foundation color conformity level has an average of 3.14. There is a foundation color difference against dark facial skin on party makeup at the foundation's smoothness level $5.029>3.55$ and foundation color compatibility level $4.031>3.55$. A suggestion to choose the appropriate foundation color that is one lighter level is mixed with one darker level.

Keywords: color foundation, dark facial skin, makeup Party

\begin{abstract}
Abstrak
Kesulitan dalam memilih warna foundation sangat berpengaruh terhadap rias wajah salah satunya yaitu rias pesta. Karena salah dalam memilih warna foundation membuat wajah belang tidak sesuai dengan warna kulit. Tujuan dalam penelitian ini untuk mengetahui
\end{abstract}

his is an open access article distributed under the Creative Commons 4.0 Attribution License, which permits unrestricted use, distribution, and reproduction in any medium, provided the original work is properly cited. $\odot 2017$ by author and Universitas Negeri Padang. 
hasil perbedaan pengaplikasian warna foundation terhadap kulit wajah gelap pada rias pesta.Jenis penelitian ini adalah eksperimen semu (quasi eksperiment) dengan desain penelitian Non Equivalent Control Group Desain. Objek dalam dalam penelitian ini adalah wanita yang memiliki kulit wajah gelap berusia 18-25 tahun dengan jumlah sampel sebanyak 3 orang.Teknik analisis data yang digunakan yaitu uji normalitas, uji homogenitas dan uji anava.Berdasarkan hasil penelitian pengaplikasian warna foundation terhadap kulit wajah gelap pada rias pesta dilihat dari indikator penilaian tingkat kehalusan foundation dan tingkat kesesuaian warna foundation. Hasil pengaplikasian warna foundation satu tingkat lebih terang memiliki rata-rata tingkat kehalusan 2,28 tingkat kesesuaian warna foundation memiliki rata-rata 2,14. Hasil pengaplikasian warna foundation satu tingkat lebih gelap tingkat kehalusan memilik rata-rata 2,14 tingkat kesesuaian warna foundation 2,28. Hasil pengaplikasian dua warna foundation satu tingkat lebih terang dicampurkan dengan satu tingkat lebih gelap tingkat kehalusan memiliki rata-rata 3,28 tingkat kesesuaian warna foundation memiliki rata-rata 3,14. Terdapat perbedaan warna foundation terhadap kulit wajah gelap pada rias pesta pada tingkat kehalusan foundation 5.029>3.55 dan tingkat kesesuaian warna foundation 4.031>3.55. Saran untuk memilih warna foundation yang sesuai yaitu satu tingkat lebih terang dicampurkan dengan satu tingkat lebih gelap .

Kata Kunci: Warna foundation, kulit wajah gelap, rias pesta

\section{Pendahuluan}

Kecantikan sangat identik dengan wanita. Setiap wanita ingin berpenampilan menarik agar memiliki kecantikan yang terpancar, baik dari dalam maupun dari luar. Kecantikan dari luar ditunjang oleh penampilan fisik, sedangkan kecantikan dari dalam terpancar bila kondisi psikis sehat dan budipekertinya (Puspita Martha, 2009) Di zaman sekarang rias wajah sangat berpengaruh besar terhadap penampilan bagi seorang wanita. Rias wajah digunakan pada acara-acara tertentu, seperti mengahadiri acara pesta teman, atau keluarga. Biasanya pada suatu pesta, kita akan bertemu dengan banyak orang. Oleh karena itu, penampilan khususnya rias wajah adalah hal yang paling utama. Dalam kesempatan itu rias wajah pesta identik dengan riasan yang glamour dan elegent. Menurut Dwikarya (2003:33) "Kriteria rias wajah pesta adalah adanya warna yang terang dan terkesan lebih berkilau khususnya dibagian mata, pipi, dan bibir, serta berkilau diseluruh riasan." Menurut Hayatunnufus (2017:141) mengatakan bahwa "Rias wajah pesta malam hari adalah riasan yang menggunakan warnawarna yang lebih menonjol biasanya digunakan untuk pesta kesempatan malam hari, dengan menggunakan foundation yang lebih menutup, misalnya pancake foundation, dapat juga dipakai jenis creamy foundation."

Merias wajah memerlukan beberapa keterampilan antara lain: memilih kosmetik yang sesuai dengan jenis kulit, mampu memilih warna riasan yang sesuai dengan warna kulit dan kesempatan. Warna kulit seseorang membawa pengaruh pada pemilihan warna kosmetik yang akan digunakan pada wajah. Untuk menentukan warna kulit seseorang dapat dilihat dengan menggunakan alat Colour Skin. Menurut Windiyanti (2019:39) “Analisis kulit berdasarkan klasifikasi warna kulit dikembangkan oleh Thomas dengan menggunakan alat ukur yang dikenal sebagai Fitzpatrick Scale. Analisis kulit menentukan klasifikasi warna kulit

This is an open access article distributed under the Creative Commons 4.0 Attribution License, which permits unrestricted use, distribution, and reproduction in any medium, provided the original work is properly cited. ( 2017 by author and Universitas Negeri Padang. 
ini sangat penting dilakukan karena toleransi setiap orang berbeda, tergantung pada tingkatan warna kulitnya".

Kulit wajah gelap memiliki kesulitan dalam pemilihan warna kosmetik, salah satunya foundation. Menurut Kusumawardhani (2008) "Kosmetik foundation merupakan salah satu kosmetik yang terpenting untuk menunjang kesempurnaan hasil riasan". Kulit wajah gelap dipengaruhi oleh banyaknya melanin, semakin banyak melanin yang terkandung didalam kulit maka kulit tersebut semakin gelap. Andiyanto (2003:31) mengemukakan bahwa "Foundation atau alas bedak berfungsi memberikan efek mulus pada wajah. Tersedia dalam beberapa tingkatan dalam bentuk cair, krim (dalam tube), padat (compact) dan stik".

Berdasarkan hasil wawancara pada tanggal 22-27 April 2019 dengan 4 narasumber yaitu Siti Marlina Make Up, Cardo Ricky Make Up, Rani Raihanilda Makeup Art, Andri Tanzil Make Up yang mana mereka pernah mendapati klien yang memiliki kulit gelap dan mengalami kesulitan saat meriasnya terutama kesulitan dalam memilih warna foundation. Foundation sangat berpengaruh pada rias wajah terutama untuk rias pesta, karena rias pesta digunakan satu hari penuh pada acara-acara tertentu, jadi foundation yang digunakan harus tahan lebih lama. Menurut Hayatunnufus (2017:57) foundation tersedia dalam beberapa tingkatan warna dalam bentuk krim (dalam tube), stik, compact (padat), juga cair.

Beberapa pendapat dari 4 nara sumber menggunakan warna foundation yang berbedabeda. Siti Marlina Make Up menggunakan foundation satu tone lebih terang dari warna kulit, biasanya juga mencampurkan foundation untuk menghasilkan warna yang mendekati dengan warna kulit. Ricky Cardo Make Up menggunakan foundation satu tone lebih terang dan satu tone lebih gelap dari warna kulit, Ricky Cardo juga menggunakan shading sebagai pencampuran warna jika tidak memiliki warna foundation yang gelap. Pendapat Rani Raihanilda Makeup Art menggunakan foundation yang biasanya memiliki shade beige dan mencampurkan warna foundation yang terang dengan foundation yang gelap. Sedangkan Andri Tanzil Make Up menggunakan warna foundation yang paling tua dan mencampurkan warna foundation yang muda dan tua.

Penelitian ini akan menggunakan warna foundation satu tingkat lebih terang, satu tingkat lebih gelap dan dua campuran warna foundation satu tingkat lebih terang dicampurkan satu tingkat lebih gelap terhadap kulit wajah gelap pada rias pesta. Dengan tujuan untuk mengetahui hasil pengaplikasian warna foundation satu tingkat lebih terang terhadap kulit gelap pada rias pesta, untuk mengetahui hasil pengaplikasian warna foundation satu tingkat lebih gelap terhadap kulit wajah gelap pada rias pesta, untuk mengetahui pengaplikasian dua warna foundation satu tingkat lebih terang dicampurkan dengan satu tingkat lebih gelap terhadap kulit wajah gelap pada rias pesta.

\section{Metode}

Jenis penelitian yang digunakan yaitu eksperimen semu (quasi eksperiment) Menurut Nazir (1983:73) "Ekspreimen semu merupakan penelitian yang mendekati percobaan sungguhan dimana tidak mungkin mengadakan kelompok kontrol/memanipulasikan semua variabel yang relevan". Desain penelitian yang digunakan Non Equivalent Control Group Desain menjelaskan perbedaan pengaplikasian warna foundation terhadap kulit wajah gelap pada rias pesta. Dengan objek penelitian wanita yang memiliki kulit wajah gelap berusia 18 e-ISSN: 2549-9823 p-ISSN: 2085-4285 
25 tahun. Sampel dalam penlitian ini bejumlah 3 orang dengan teknik pengambilan sampel dengan purvosing sample yaitu teknik penentuan sampel dengan pertimbangan tertentu (Sugiyono 2006:95). Teknik pengumpulan data yang digunakan yaitu metode observasi, dokumnetasi dan isntrume penilaian. Teknik analisis data yang digunakan yaitu uji normalitas, uji homogenitas dan uji anava

\section{Hasil Dan Pembahasan}

Hasil

Distribusi Rata-Rata Hasil Tingkat Kehalusan Foundation dan Kesesuaian Warna Foundation Pada Eksperimen Warna Foundation Satu Tingkat Lebih Terang (X1), Satu Tingkat Lebih Gelap (X2) dan Dua Warna Foundation Satu Tingkat Lebih Terang Dicampurkan Satu Tingkat Lebih Gelap (X3)

Table 1 Tabel Distribusi

\begin{tabular}{lllllll}
\hline Indikator Penilaian & Hasil Ukur & Mean & SD & Min & Maks & N \\
\hline Kehalusan Foundation & $\mathrm{X} 1$ & 2.29 & 0.756 & 1 & 3 & 7 \\
\cline { 2 - 7 } & $\mathrm{X} 2$ & 2.14 & 0.690 & 1 & 3 & \\
\cline { 2 - 6 } & $\mathrm{X} 3$ & 3.29 & 0.756 & 2 & 4 & \\
\hline \multirow{2}{*}{$\begin{array}{l}\text { Kesesuaian Warna } \\
\text { Foundation }\end{array}$} & $\mathrm{X} 1$ & 2.14 & 0.690 & 1 & 3 & 7 \\
\cline { 2 - 6 } & $\mathrm{X} 2$ & 2.29 & 0.756 & 1 & 3 & \\
\cline { 2 - 6 } & $\mathrm{X} 3$ & 3.14 & 0.690 & 2 & 4 \\
\hline
\end{tabular}

Rata-rata pada indikator kehalusan foundation pada eksperimen 1 (X1) adalah sebesar 2.29 dengan standar deviasi \pm 0.756 , nilai minimum 1 dan nilai maksimum 3 , nilai rata-rata eksperimen 2 (X2) adalah sebesar 2.14 dengan standar deviasi \pm 0.690 , nilai minimum 1 dan nilai maksimum 3, nilai rata-rata eksperimen 3 (X3) adalah sebesar 3.29 dengan standar deviasi \pm 0.690 , nilai minimum 2 dan nilai maksimum 4 .

Rata-rata pada indikator tingkat kesesuaian warna foundation pada eksperimen 1 (X1) sebesar 2.14 dengan standar deviasi \pm 0.690 , nilai minimum 1 dan nilai maksimum 3 , ratarata eksperimen 2 (X2) adalah sebesar 2.29 dengan standar deviasi \pm 0.756 , nilai minimum 1 dan nilai maksimum 3, rata-rata eksperimen 3 (X3) adalah sebesar 3.14 dengan standar deviasi \pm 0.690 , nilai minimum 2 dan nilai maksimum 4 .

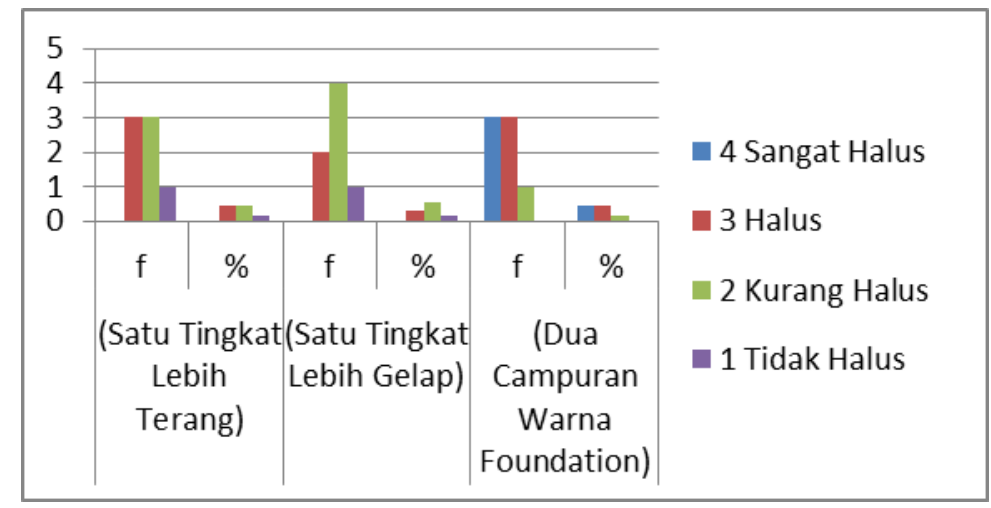

This is an open access article distributed under the Creative Commons 4.0 Attribution License, which permits unrestricted use, distribution, and reproduction in any medium, provided the original work is properly cited. (C2017 by author and Universitas Negeri Padang. 
Gambar 1. Histogram Distribusi Frekuensi Hasil Tingkat Kehalusan Foundation Pada Eksperimen X1, X2, X3

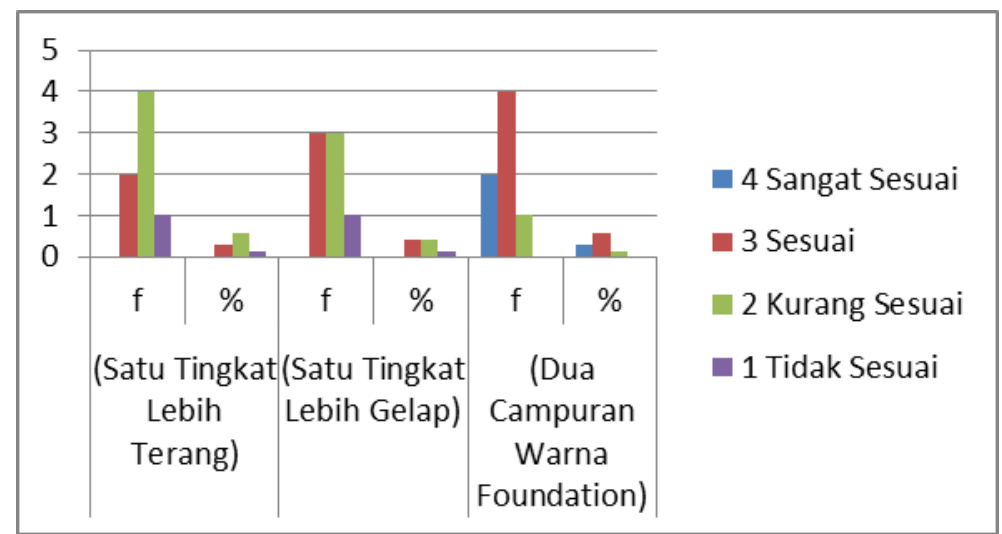

Gambar 2. Histogram Distribusi Frekuensi Hasil Tingkat Kesesuaian Warna Foundation Pada Eksperimen X1, X2, X3

Uji Persyaratan Analisis.

Uji persyaratan yang dilakukan yaitu uji Normalitas, Homogenitas dan uji Anava.

\section{Uji Normalitas}

Table 2 Uji Normalitas terhadap tingkat kehalusan foundation

\begin{tabular}{lllllll}
\hline & \multicolumn{3}{l}{ Kolmogorov-Smirnov } & \multicolumn{3}{l}{ Shapiro-Wilk } \\
\cline { 2 - 7 } & Statistik & $d f$ & Sig. & Statistik & $d f$ & Sig. \\
\hline X1 & 0.256 & 7 & 0.182 & 0.833 & 7 & 0.086 \\
\hline X2 & 0.296 & 7 & 0.063 & 0.840 & 7 & 0.099 \\
\hline X3 & 0.256 & 7 & 0.182 & 0.833 & 7 & 0.086 \\
\hline
\end{tabular}

Karena sampel kurang dari 50, maka penggunaan uji normalitas menggunakan ShapiroWilk, dan didapatkan hasil dari X1 0.086, X2 0.099, X3 0.086 yaitu > 0.05 maka data terdistribusi normal.

Table 3 Uji Normalitas terhadap tingkat kesesuaian warna foundation

\begin{tabular}{lllllll}
\hline & \multicolumn{3}{l}{ Kolmogorov-Smirnov } & \multicolumn{4}{l}{ Shapiro-Wilk } \\
\cline { 2 - 7 } & Statistik & $d f$ & Sig. & Statistik & $d f$ & Sig. \\
\hline X1 & 0.296 & 7 & 0.063 & 0.840 & 7 & 0.099 \\
\hline X2 & 0.256 & 7 & 0.182 & 0.833 & 7 & 0.086 \\
\hline X3 & 0.296 & 7 & 0.063 & 0.840 & 7 & 0.099 \\
\hline
\end{tabular}

Karena sampel kurang dari 50, maka penggunaan uji normalitas menggunakan ShapiroWilk, dan didapatkan hasil dari X1 0.099, X2 0.086, X3 0.099 yaitu > 0.05 maka data terdistribusi normal

\section{Uji Homogenitas}

Table 4 Rangkuman Uji Homogenitas Terhadap Kehalusan Foundation e-ISSN: 2549-9823 p-ISSN: 2085-4285 


\begin{tabular}{llll}
\hline Levene Statistic & Df1 & Df2 & Sig. \\
\hline 0.226 & 2 & 18 & 0.800 \\
\hline
\end{tabular}

Table 5 Rangkuman Uji Homogenitas Terhadap Kesesuaian Foundation

\begin{tabular}{llll}
\hline Levene Statistic & DfI & Df2 & Sig. \\
\hline 0.199 & 2 & 18 & 0.821 \\
\hline
\end{tabular}

\section{Uji Anava}

Table 6 Uji ANAVA indikator tingkat kehalusan foundation

\begin{tabular}{lllcll}
\hline & Sums Of Squares & df & $\begin{array}{c}\text { Mean } \\
\text { Squares }\end{array}$ & F & Sig \\
\hline $\begin{array}{l}\text { Between } \\
\text { Groups }\end{array}$ & 5.429 & 2 & 2.714 & 5.029 & 0.018 \\
\hline Within Groups & 9.714 & 18 & 0.540 & & \\
\hline Total & 15.143 & 20 & & &
\end{tabular}

Berdasarkan perhitungan Anava dapat terlihat bahwa tingkat kehalusan foundation terdapat $\mathrm{F}_{\text {hitung }}>\mathrm{F}_{\text {tabel }}(5.029<3.55)$ hal ini membuktikan bahwa hipotesis yang berbunyi tterdapat perbedaan hasil yang signifikan pada pengaplikasian warna foundation satu tingkat lebih terang, satu tingkat lebih gelap dan dua warna foundation satu tingkat lebih terang dicampurkan dengan satu tingkat lebih gelap terhadap kulit wajah gelap pada rias pesta diterima.

Table 7 Uji ANAVA indikator kesesuaian warna foundation

\begin{tabular}{|c|c|c|c|c|c|}
\hline & $\begin{array}{c}\text { Sums } \\
\text { Squares }\end{array}$ & ( df & $\begin{array}{c}\text { Mean } \\
\text { Squares }\end{array}$ & $\mathrm{F}$ & Sig \\
\hline Between Groups & 4.095 & 2 & 2.048 & 4.031 & 0.036 \\
\hline Within Groups & 9.143 & 18 & 0.508 & & \\
\hline Total & 13.228 & 20 & & & \\
\hline
\end{tabular}

Berdasarkan perhitungan Anava dapat terlihat bahwa tingkat kesesuaian terdapat $\mathrm{F}_{\text {hitung }}<$ $\mathrm{F}_{\text {tabeI }}(0,706<161)$ hal ini membuktikan bahwa hipotesis yang berbunyi tidak terdapat perbedaan hasil yang signifikan pada pengaplikasian warna foundation satu tingkat lebih terang, satu tingkat lebih gelap dan dua warna foundation satu tingkat lebih terang dicampurkan dengan satu tingkat lebih gelap terhadap kulit wajah gelap pada rias pesta diterima.

\section{Pembahasan}


Pembahasan berikut ini akan mengemukakan deskripsi data hasil penelitian yang diperoleh, berikut uraian tentang pembahasan hasil dari penelitian:

\section{Pengaplikasian Warna Foundation Satu Tingkat Lebih Terang Terhadap Kulit Wajah Gelap Pada Rias Pesta}

Berdasarkan analisis data yang dikemukakan berhubungan dengan hasil penelitian terhadap sampel kulit wajah gelap dengan pemgaplikasian warna foundation satu tingkat lebih terang pada rias pesta (X1) dinyatakan hasil penilaian pada indikator tingkat kehalusan memperoleh skor rata-rata 2,28 dikategorikan kurang halus, dan tingkat kesesuaian warna foundation memperoleh skor rata-rata 2,14 dikategorikan kurang sesuai.

\section{Pengaplikasian Warna Foundation Satu Tingkat Lebih Gelap Terhadap Kulit Wajah Gelap Pada Rias Pesta.}

Berdasarkan analisis data yang dikemukakan berhubungan dengan hasil penelitian terhadap sampel kulit wajah gelap dengan pemgaplikasian warna foundation satu tingkat lebih gelap pada rias pesta (X2) dinyatakan hasil penilaian pada indikator tingkat kehalusan memperoleh skor rata-rata 2,14 dikategorikan kurang halus, dan tingkat kesesuaian warna foundation memperoleh skor rata-rata 2,28 dikategorikan kurang sesuai.

\section{Pengaplikasian Dua Warna Foundation Satu Tingkat Lebih Terang Dicampurkan \\ Dengan Satu Tingkat Lebih Gelap Terhadap Kulit Wajah Gelap Pada Rias Pesta}

Berdasarkan analisis data yang dikemukakan berhubungan dengan hasil penelitian terhadap sampel kulit wajah gelap dengan pengaplikasian dua warna foundation satu tingkat lebih terang dicampurkan dengan satu tingkat lebih gelap pada rias pesta (X3) dinyatakan hasil penilaian pada indikator tingkat kehalusan memperoleh skor rata-rata 3,28 dikategorikan halus, dan tingkat kesesuaian warna foundation memperoleh skor rata-rata 3,14 dikategorikan sesuai. Hal ini sesuai dengan hasil wawancara bersama penata rias yaitu Ricky Cardo Make Up dan Andri Tanzil Make Up mengatakan bahwa " untuk kulit wajah gelap menggunakan dua warna foundation satu tingkat lebih terang dan satu tingkat lebih gelap kedua foundation tersebut dicampurkan atau menggunakan warna muda dan tua dicampurkan agar mendapatkan warna yang sesuai dengan warna kulit".

\section{Perbedaan hasil pengaplikasian warna foundation satu tingkat lebih terang terhadap kulit wajah gelap pada rias pesta (X1) pengaplikasian warna foundation satu tingkat lebih gelap terhadap kulit wajah gelap pada rias pesta (X2) pengaplikasian dua warna foundation satu tingkat lebih terang dicampurkan dengan satu tingkat lebih gelap terhadap kulit wajah gelap pada rias pesta (X3). \\ Hasil penelitian pada tingkat kehalusan menunjukkan bahwa $\mathrm{F}_{\text {hitung }}$ sebesar (5.029) dan $\mathrm{F}_{\text {tabel }}$ sebesar (3.55). Harga $\mathrm{F}_{\text {hitung }}>\mathrm{F}_{\text {tabel }}(5.029>3.55)$ membuktikkan bahwa hipotesis yang berbunyi terdapat perbedaan hasil pengaplikasian warna foundation terhadap kulit wajah gelap pada rias pesta pada indikator tingkat kehalusan foundation, itu berat diterima pada taraf signifika $0,05 . \mathrm{H}_{0}$ ditolak dengan makna terdapat perbedaan hasil pengaplikasian warna foundation satu tingkat lebih terang, satu tingkat lebih gelap dan dua warna foundation satu tingkat lebih terang dicampurkan dengan satu tingkat lebih gelap terhadap kulit wajah gelap pada rias pesta.}

e-ISSN: 2549-9823 p-ISSN: 2085-4285 
Hasil penelitian pada tingkat kehalusan menunjukkan bahwa $\mathrm{F}_{\text {hitung }}$ sebesar (4.031) dan $\mathrm{F}_{\text {tabel }}$ sebesar (3.55). Harga $\mathrm{F}_{\text {hitung }}>\mathrm{F}_{\text {tabel }}(4.031>3.55)$ membuktikkan bahwa hipotesis yang berbunyi tidak terdapat perbedaan hasil pengaplikasian warna foundation terhadap kulit wajah gelap pada rias pesta pada indikator tingkat kesesuaian warna foundation, itu berarti diterima pada taraf signifika $0,05 . \mathrm{H}_{\circ}$ ditolak dengan makna terdapat perbedaan hasil pengaplikasian warna foundation satu tingkat lebih terang, satu tingkat lebih gelap dan dua warna foundation satu tingkat lebih terang dicampurkan dengan satu tingkat lebih gelap terhadap kulit wajah gelap pada rias pesta.

Berdasarkan kajian hasil penelitian mengenai perbedaan hasil pengaplikasian warna foundation satu tingkat lebih terang, satu tingkat lebih gelap dan dua warna foundation satu tingkat lebih terang dicampurkan dengan satu tingkat lebih gelap terhadap kulit wajah gelap pada rias pesta menyatakan bahwa terdapat perbedaan pada 3 eksperimen tersebut.

Hal ini membuktikkan bahwa penggunaan dua warna foundation satu tingkat lebih terang dicampurkan satu tingkat lebih gelap terhadap kulit wajah gelap pada rias pesta lebih sesuai untuk digunakan pada kulit wajah gelap. Karena penggunaan foundation sangat penting dalam riasan dan menjadi pondasi dalam rias pesta, penggunaan warna foundation yang salah tidak sesuai dengan warna kulit akan membuat kulit menjadi seperti topeng dan tekstur tidak halus. Setelah dilakukan penelitian maka dua warna foundation satu tingkat lebih terang dicampurkan dengan satu tingkat lebih gelap lebih sesuai dan cocok untuk diaplikasikan pada kulit wajah gelap. Hal ini sesuai dengan pendapat 4 penata rias di kota Padang yang telah diwawancari pada tanggal 24-27 april mengatakan "Siti Marlina Make Up menggunakan foundation satu tone lebih terang dari warna kulit, biasanya juga mencampurkan foundation untuk menghasilkan warna yang mendekati dengan warna kulit. Ricky Cardo Make Up menggunakan foundation satu tone lebih terang dan satu tone lebih gelap dari warna kulit, Ricky Cardo juga menggunakan shading sebagai pencampuran warna jika tidak memiliki warna foundation yang gelap. Pendapat Rani Raihanilda Makeup Art menggunakan foundation yang biasanya memiliki shade beige dan mencampurkan warna foundation yang terang dengan foundation yang gelap. Sedangkan Andri Tanzil Make Up menggunakan warna foundation yang paling tua dan mencampurkan warna foundation yang muda dan tua.

\section{Simpulan dan Saran}

\section{Simpulan}

Berdasarkan hasil penelitian yang telah dilakukan maka dapat diambil kesimpulan sebagai berikut: (1) Distribusi skor rata-rata tingkat kehalusan foundation pada eksperimen 1 (X1) adalah 2,28 distribusi skor rata-rata ekperimen 2 (X2) 2,14 dan distribusi skor rata-rata eksperimen 3 (X3) 3,28. Dengan demikian terdapat perbedaan secara signifikan. (2) Distribusi skor rata-rata tingkat kesesuaian warna foundation pada eksperimen 1 (X1) 2,14 distribusi skor rata-rata eksperimen 2 (X2) 2,28 dan distribusi skor rata-rata eksperimen 3 (X3) 3,14. Dengan demikian terdapat perbedaan secara signifikan dari ketiga perlakuan yang berbeda. Perhitungan hasil pengaplikasian warna foundation sati tingkat lebih terang, satu tingkat lebih gelap dan dua warna foundation satu tingkat lebih terang dicampurkan dengan satu tingkat lebih gelap terhadap kulit wajah gelap pada rias pesta dengan indikator penilai

This is an open access article distributed under the Creative Commons 4.0 Attribution License, which permits unrestricted use, distribution, and reproduction in any medium, provided the original work is properly cited. ( 2017 by author and Universitas Negeri Padang. 
tingkat kehalusan foundation menyatakan bahwa nilai F_hitung > F_tabel (5.029>3.55), pada tingkat kesesuaian warna foundation menyatakan bahwa F_hitung > F_tabel (4.031>3.55). Hal ini membuktikan bahwa hipotesis yang berbunyi tidak terdapat perbedaan hasil pengaplikasian warna foundation satu tingkat lebih terang, satu tingkat lebih gelap dan dua warna foundation satu tingkat lebih terang dicampurkan dengan satu tingkat lebih gelap terhadap kulit wajah gelap pada rias pesta pada indikator tingkat kehalusan foundation dan tingkat kesesuaian warna foundation diterima pada taraf signifikan 0,05. H_o ditolak dengan makna bahwa terdapat perbedaan hasil hasil pengaplikasian warna foundation satu tingkat lebih terang, satu tingkat lebih gelap dan dua warna foundation satu tingkat lebih terang dicampurkan dengan satu tingkat lebih gelap terhadap kulit wajah gelap pada rias pesta.

\section{Saran}

Setelah melakukan penelitian ini maka dapat dikemukakan saran-saran yang diberikan kepada penerima manfaat penelitian, yaitu: (1) Bagi jurusan Tata Rias dan Kecantikan, hasil penelitian ini dapat dijadikan masukan pengetahuan pada mata kuliah Rias Wajah Pesta. (2) Bagi mahasiswa program studi D4 Pendidikan Tata Rias dan Kecantikan, hasil penelitian ini dapat memberikan ilmu pada rias wajah pesta dengan pengaplikasian warna foundation satu tingkat lebih terang, satu tingkat lebih gelap dan dua warna foundation satu tingkat lebih terang dicampurkan dengan satu tingkat lebih gelap terhadap kulit wajah gelap. (3) Bagi responden, hasil penelitian ini dapat bermanfaat dalam merias wajah pesta. Disarankan untuk memilih dua warna foundation satu tingkat lebih terang dicampurkan dengan satu tingkat lebih gelap karena hasil akhir yang didapatkan sesuai dengan warna kulit wajah gelap. (4) Bagi peneliti, selain syarat untuk menyelesaikan pendidikan juga merupakan kesempatan untuk berlatih mengaplikasikan warna foundation dengan melakukan eksperimen dan dapat menerapkan ilmu-ilmu yang telah diperoleh.Saran

\section{Daftar Pustaka}

Assara Qemha, Rahmiati dan Linda Rosalina . 2016. Hubungan Pengetahuan Dengan Andiyanto. 2003. The Make Over Rahasia Rias Wajah Sempurna. Jakarta : Gramedia Pustaka Utama

Dwikarya, Maria. 2003. Merawat Kulit dan Wajah. Jakarta: Penerbit Kawan Pustaka Hayatunnufus dan Siska Miga Dewi. 2017. Tata Rias Wajah. Padang: UNP Press

Kusumawardhani, Reni. 2008. Miracle Make-Up. Jakarta: Gramedia Pustaka Utama Nazir Mohammad. 1983. Metode Penelitian. Jakarta: Ghalia Indonesia

Tilaar, Martha. 2009. Maximise Your Beauty. PT. Creative Stglemandiri. Jakarta

Windiyai. 2019. Perawatan Kecantikan Kulit. Jakarta : Gramedia Pustaka Utama 